\title{
Studying Languages Remotely: Reflections on Challenges Posed by Distance Learning
}

\author{
Tetiana Dombrovan * [0000-0003-3119-5499], Olena Mitina ${ }^{[0000-0001-8732-2421]}$
}

Odesa National Polytechnic University, Odesa, Ukraine

*dombrovanti@gmail.com

\begin{abstract}
The process of introducing distance learning into the education system in different countries has its own characteristics. Distance learning is a motivating factor in learning foreign languages, contributes to the achievement of personal, meta subject, subject learning outcomes and, ultimately, the achievement of the goal of teaching foreign languages: the formation of foreign language communicative competence. The specificity of the subject "Foreign language" is primarily due to the fact that the leading component of the content of teaching a foreign language is not the basics of science, but methods of activity are teaching various types of speech activity: speaking, listening, reading and writing. Distance learning contributes to the implementation of modern educational paradigms such as individualization and differentiation of educational activities, self-education and self-development of trainees.
\end{abstract}

Keywords: distance learning, challenges, respondent, survey, foreign language.

\section{INTRODUCTION}

It is for more than a year now that the whole world has been suffering from the COVID-19 pandemic and the impact it has already had in most spheres of human activity. Not only has the pandemic revealed how small and fragile our world is, but it has also exposed longstanding critical problems in medicine and health care, policy-making, economy development, environment protection, education, to mention just few.

It is for more than a year now that the whole world has been suffering from the COVID-19 pandemic and the impact it has already had in most spheres of human activity. Not only has the pandemic revealed how small and fragile our world is, but it has also exposed longstanding critical problems in medicine and health care, policy-making, economy development, environment protection, education, to mention just few.

Education crises manifests, first of all, in shutting down schools and colleges all over the world. According to the UN Educational, Scientific and Cultural Organization (UNESCO), more than 1.5 billion students and youth across the planet are or have been affected by school and university closures due to the COVID-19 pandemic [1], which may lead to negative consequences in the nearest future. In other words, "loss of access to education not only diminishes learning in the short term but also increases long-term dropout rates and reduces future socioeconomic opportunities" [2]. In this still unpredictable context, an appropriate solution to the pandemic challenge is seen in expansion of access to education via distance, or remote, learning.

Below, this article reports on the assessment of implementation of online technologies in distance learning of foreign languages at Odessa National Polytechnic University (ONPU) during two quarantine periods covering the most part of the spring semester and that of the autumn semester of 2020.

\section{PURPOSE AND METHODS OF RESEARCH}

The purpose of the article is to estimate the effectiveness of employment of online educational platforms for teaching English at ONPU in order to improve the organization of distance learning in further use in higher-education process.

To achieve the purpose, a number of investigation tasks are to be considered, such as:

1) to examine formats of distance learning; 
2) to outline educational platforms and internet resources suitable for English lessons;

3) to consider challenges posed to teachers by distance learning;

4) to monitor students' attitudes towards distance learning on the whole and their learning outcomes in particular.

Methodologically, the present analysis is based on the data obtained through a survey of challenges and impact of distance learning, in which more than a hundred respondents from ONPU expressed their attitude, among them being: 1) fifty students majoring in general English and technical translation, 2) eighty-two undergraduates doing their Master degree in sciences and studying ESP (English for Specific Purposes), and 3) eight lecturers teaching different aspects of English - grammar, vocabulary, reading comprehension, technical English, English for business communication, ESP, etc.

Data collection was carried out on a voluntary basis. The respondents were acquainted with the objectives of the study and how to complete the questionnaire. They were asked to use points from 0 to 5 in their answers, where 0 stood for 'very poor' and 5 meant 'excellent'. The questions were formulated in such a way so as to find out: 1) the respondents' opinion about technical potential of using online technologies in ONPU (e.g. computerequipped classrooms, availability of the necessary software, a good internet speed to support online activities, etc.); 2) the respondents' opinion about the structure and content of online lessons (e.g. the quality of teaching materials, the possibility of self-education, the objectivity of the system of assessment of students' knowledge, etc.); 3) the needs of the participants of distance education process, i.e. their weak points; 4) advantages and drawbacks of .studying (languages) online. To obtain a more or less objective picture, both the teachers and the students were asked nearly the same questions.

The main methods of the present study are empirical and interpretive. The empirical methods consisted in conducting the survey of ONPU instructors' and fulltime students' opinions about online English classes and their recommendations on how to improve effectiveness of distance education at the university. The interpretive methods included the comprehensive and systematic study of the key problem, the comparative analysis of the obtained data, generalization of teachers' and learners' experience, etc.

The results of the survey are analyzed below.

\section{THEORETICAL BACKGROUND OF RESEARCH}

Distance, or remote, education is defined as a type of educational process conducted outside of a traditional classroom face-to-face (F2F) environment. The United States Distance Learning Association (USDLA) distinguishes between distance teaching (a teacher's activity in the educational process) and distance learning (a student's cognitive activity). Among the key factors determining the distance form of education are the following two: first, (geographical) distancing between a tutor and a learner; and second, priority of a student's self-control over control by the teacher.

It is far from being a novel notion in education, since this mode of learning has been used for years by students who, for a number of reasons, are not able to attend higher schools and / or colleges.

Though its aim has changed little, the format of distance learning has obviously evolved for the past years.

Formerly, remote learning occurred in the form of correspondence between a student and the instructor: a student was given an assignment to be accomplished and sent via post by a certain date, then, the instructor checked and marked the paper. Such mode of learning allowed students to study at their individual pace and in the familiar (home) environment. The most significant drawback of distance learning was that students lacked real-time communication with teachers and teamwork with peers.

Nowadays, not only has distance learning considerably extended since early 2020 , but it has also developed its forms. Today, distance learning incorporates a wide use of technological instruments to convey information to students and back to their teacher. It can occur either synchronously or asynchronously. Synchronous distance learning suggests students' collaboration with one another and interaction with the teacher within real-time communication, while asynchronous distance learning focuses on students' self-paced activities performed without the immediate instructions on the teacher's side [3].

'Distance learning' is used as the so-called umbrella term for any type of learning which excludes immediate presence in the same classroom of participants of the teaching-learning process. Heterogeneity of distance learning is represented by a number of types, the main ones being:

- online learning (also called e-learning), which can be either synchronous or asynchronous and is performed via Internet educational platforms;

- video conferencing as a means of live real-time communication between participants;

- hybrid, or blended, learning, i.e. combination of online and offline methods of education.

Distance learning methodologies empower both teachers and students with a certain flexibility and 
freedom in organizing the educational interaction in accordance with the main principles of Universal Design for Learning (UDL): 1) the engagement principle (or thewhy?-of learning); 2) the representation principle (thewhat?-of learning), and 3) the action and expression principle (the-how?-of learning). Created by CAST, which is a US nonprofit education research and development organization, Universal Design for Learning is a framework of guidelines aimed at optimizing teaching, improving learning and making it inclusive for everyone [4].

Reforms in the higher-school education of Ukraine shift the focus on the student's personal development, which is in line with the UDL principles. The competence-based approach that is being introduced to replace the knowledge approach, in its turn, necessitates the development of new teaching methods, as well as new technologies for testing and assessing students' competencies [5].

The wide-scale transition of higher schools to distance learning, accelerated by the pandemic, has resulted in reconsidering the amount of learning materials, in facilitation of e-learning methods.

\section{DISTANCE LEARNING PLATFORMS: A BRIEF OUTLINE}

To be effective, any kind of learning interaction is to be well-organized and comfortable for both a teacher and a student/students. Our research has made it possible to list the educational platforms and sites which were most frequently used by lecturers and instructors at Odessa National Polytechnic University during the above outlined time-frame. This list includes:

- Google Classroom, which is a free and easy-touse service suitable for asynchronous learning. Not only is it far from difficult to set up, but it is also timesaving allowing teachers to create and check assignments, and students - to share resources and work in teams [6].

- Microsoft Team [7] offers a wide range of services, such as video conferencing, screen sharing, group chatting, file sharing, making and receiving calls within groups, streamline collaboration, chat translation and even sending stickers and emojis.

- In 2019, Zoom became the leader in video conferencing and webinars, reports Gartner Magic Quadrant [8]. It is used for synchronous communication and can be easily installed on any device and is compatible with any operational system. Zoom is good for lectures and teamwork; it allows the teacher to share a presentation, to perform a video and to use a screen as a writing board.

- MyEnglishLab-Pearson [9] is a part of Pearson course, offering online support of four-level educational textbooks and workbooks by Pearson. This is a great helper for both teachers and students in extending the Pearson courses by using video and audio content matching the topics. It can be used by students as an online workbook with extra support, tips and feedback; it offers teachers automated marking of students' homework, as well as tools for viewing progress and messaging. MyEnglishLab-Pearson turned out very helpful in English grammar lessons (levels B1-B2 and C1-C2) and classes in Business English (level B2+).

- the global education network Edmodo, which is a distance learning platform with in-built communication and collaboration tools allowing both online and F2F and a hybrid of the two. It is called a hub for learning as it offers a flexible classroom space, tools for building interactive lessons, access to educational resources [10]. Edmodo supports synchronous and asynchronous learning to fully meet the needs of the participants of the education process, and has a gradebook to measure student progress. [11].

- a free sticky and canvas service Lino that requires a Web browser [12]. It can be used to create a virtual board allowing several users to work on the same project by creating, editing and sharing information. It is suitable for teamwork and group discussions, taking notes and posting videos.

- $\quad$ Another free platform is Wakelet [13], which is intended for saving text- and video-content from across the web, organising it into collections and sharing with learners. Any user is free to make up their own library with thematically arranged content.

- $\quad$ The platform Nearpod [14] aims to help the teacher to make every lesson interactive in any environment - online, offline or hybrid. It is user-friendly for creating presentations; what is more, it offers its own standards-aligned library of under a thousand of interactive lessons and videos on different subjects.

- And last but not least on our list is TED - an online platform for conferences [15]. Started in 1984 as a conference about Technology, Entertainment, Design, TED offers talks on education, personal growth, communication, child development and many other topics. TED contains a wealth of authentic speeches useful for developing both listening and speaking skills of students. Problems raised by speakers can be further discussed by learners in groups.

As can well be seen, the use of various online resources in education suggests that a teacher (and a student) have to be well-equipped with technological devices and should know how to use them effectively. As our survey shows, this proved to be a challenge, at first; but before long, teachers coped with it more or less successfully. In most cases, they chose one or two online platforms to communicate with students; the choice was greatly determined by the learning goals. 


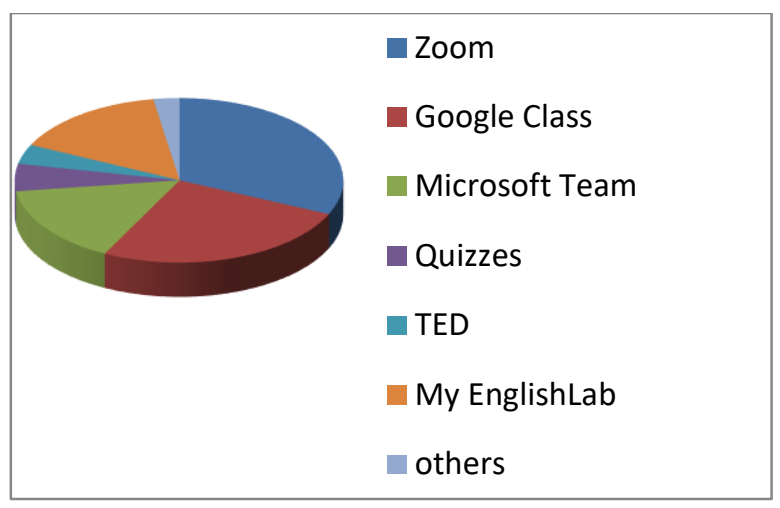

Figure 1 The use of online resources in learning languages at ONPU (2020)

However, the technical aspect was not the only hurdle to be jumped over. It soon became quite obvious that traditional classroom lessons cannot be automatically translated to the online format.

\section{DISTANCE LEARNING: TEARCHERS' VIEWS}

Forced to switch to the digital world in order to teach remotely, university instructors (as well as school teachers) immediately faced a number of challenges, which, as our research shows, can be roughly grouped into what we may call 1) technological and 2) didactic. Let us consider them more closely.

The technological challenge lies within many issues. First and foremost, it is about digital literacy of those who up to lately used to teach face-to-face in classrooms with paper textbooks and workbooks, a whiteboard and hand-outs, but now, outside a traditional educational environment, has to seek new - technological - means of teaching. The new means call for new devices, so a laptop and / or a tablet with a reliable access to internet have already become a must for a teacher (and for a student, too). A next step was to master the functional possibilities of the devices and reshape teaching skills. This leads to the other group of challenges, namely didactic.

The didactic challenge consisted in an obvious impossibility of automatic translation of traditional teaching methods and lesson material into the frames of remote education. There appeared an urgent need in training teachers not only how to use digital resources to their full but also how to re-format the lesson pattern.

It is noteworthy that academic disciplines are different not only regarding the object of study: they offer their students unalike lists of skills and competences to develop. This implies varied approaches to online teaching different disciplines.

Like many others, the academic discipline 'The English language' has a set of aims: educational (e.g. to develop students' general competences, including the ability to learn, to self-evaluate, a capacity for autonomous learning), cognitive (e.g. to further develop students' cognitive abilities through academic activities), social (e.g. to facilitate their critical self-awareness and interpersonal skills), socio-cultural and others.

The peculiarity of the "The English language" discipline is seen in its practical goal which is not only to master students' linguistic competences, but also to equally master their communicative competences to function effectively in culturally diverse academic and professional environments. Taking into account the diversity of students' learning needs and their language proficiency background, as well as the fact that 'The English language' is far from being an exceptionally theoretical discipline, it appeared impossible to project traditional teaching patterns directly to a distance format. Research shows that effective distance learning of a foreign language should be based on a well-built virtual language environment. The latter requires high labor costs, especially in the first stages of the course creation [16].

During the 2020 quarantine period, it became very important to set up and provide communicative continuity with students. In order to keep in touch with them, our teachers crafted groups on the Google class platform and in social nets; corresponding via e-mail and apps on mobile smart phones was also used to maintain the contact. These paths were good both for communication and for distributing updated materials. The students were informed where to find assignments, when and how to do their homework, where to send it back, etc. The Google Drive proved to be helpful for these purposes, too. Synchronous communication was carried via online conferences (e.g. Zoom).

However, some of the students had access to internet through mobile phones only, which set a necessity for our teachers to convert distributed materials to PDF-format or the like to be read on a phone. Another problem was with out-of-date phones with too limited capacities (e.g. the phone memory size) to install and support necessary applications. Provision of students and teachers with technically complex devices (mobile phones, laptops, PCs, iPods, etc.) became one of decisive factors in their uninterrupted communication in a new (educational) environment.

One more challenge posed to teachers was how to assess students' progress, on the whole, and their receptive and productive skills, in particular. Receptive skills are usually assessed in reading / listening sections of a lesson. Students show their ability to understand the message of the text, its main points and specific information, to identify the overt structure and genre features of a text, etc. Productive skills of students are assessed in writing and speaking. Learners reveal their ability to express their ideas about the subject in the appropriate style, grammatically correct and with accurate use of topic vocabulary, clearly structured, and with a target recipient on mind. Not only has distance learning 
reshaped the content of a traditional English lesson but it has also brought about changes in the ways of supervising students' achievements. Modern technologies simplify this task and automate this process, allowing the computer to check the material itself (e.g. MyEnglishLab-Pearson platform).

According to our survey, teachers see the following advantages of distance learning:

- Remote learning is effective in the way it nullifies geographic distances between participants of the educational process and enables an instructor to supervise a student's scientific / academic work;

- Access through Internet to a wide amount of scientific information necessary for the student's research;

- A possibility for students and teachers to contact with one another within groups and beyond;

- A certain psychological tension that can emerge between a student and a teacher during F2F communication is neutralized in distance education, which is comfortable for students primarily;

- Though the teacher's role still remains significant, in distance education it is the ability of students to self-study and self-development that becomes very important. This increases students' responsibility, too.

- The distance format offers great opportunities for students to plan their individual education trajectory both in terms of content and time frame.

Summing up, teachers do their best to maintain the educational process uninterrupted. We can't but agree with Francine Conway, PhD, dean of the Graduate School of Applied and Professional Psychology at Rutgers University, who says, "Online learning is here whether we like it or not, and it's time our profession embraces it." [17].

\section{DISTANCE LEARNING: STUDENTS' VIEWS}

Distance learning was a new format for students, too. Our survey shows that 41 per cent of the respondents expressed their positive attitude towards DL, while 48 per cent of the students said they were neutral about it. The minor rest said they missed traditional classroom environment.

One of advantages of distance learning was seen by the students in saving time spent on getting to the university and then back home $(21.7 \%)$. For 18.4 percent of respondents, the opportunity to study in a comfortable home environment ("with a cup of tea and a cat purring on my lap', in one student's response) was preferable.

The main drawback in organizing remote work, as $24.4 \%$ of respondents remarked, was caused by technical problems such as insufficient speed of home Internet, poor quality of connection, the lack of the necessary headset headphones with a microphone fixed to them, good resolution cameras, etc.

Obviously, students have different ideas about the format of training. But many of them, including freshmen, want to continue attending face-to-face classes. Of the total number of our respondents, $53 \%$ would not like to study remotely. It is also important that practical classes in foreign languages (German, English) should be held in person, they say.

The students mentioned that distance learning format is not quite suitable for practical and laboratory classes, as well as for the final certification in either obligatory or selected disciplines: $45.1 \%$ of respondents said that they would refuse to defend term papers in distance mode.

Possible forms of organization of remote education were assessed by the survey participants as follows. Combined, or blended, learning, when all possible forms of communication between a teacher and students are used, was chosen by $59.0 \%$. Synchronous learning (lectures and seminars on academic disciplines such as Foreign language, Logic, Philosophy, Natural sciences (Physics, Biology, Mathematics) in real time on online platforms) was preferred by $29.5 \%$. Only every tenth respondent chose the option of asynchronous learning, when it is necessary to master lectures on notes and study independently in the humanities (Pedagogy, History, Sociology) $-10.4 \%$.

When asked about disadvantages of distance mode, our respondents put in the first place social factors, including the lack of student life $(83.4 \%)$, the lack of peer communication $(19.2 \%)$ and direct communication with teachers $(18.2 \%)$. Many of the students mentioned that online learning demands motivation to keep progress. These answers point to the issues of distance learning which require special attention, as they show that social interaction is an important and significant part not only in education but in a human life.

Learning remotely, more than half of the students reported that they had faced a number of technical problems related to server congestion, lack of access to platforms on which training sessions were conducted, instability of Internet connection, problems with video or audio apps, etc. One in five respondents noted insufficient characteristics of their computer equipment, and $22 \%$ of applicants indicated the lack of necessary technical devices [18] (a webcam, a headset, etc.). Also, almost every fourth applicant has difficulty accessing the Internet and other technical problems.

The main advantage of social networks is their high mobility and efficiency; they are helpful as a bulletin board to exchange information between a teacher and students. The Zoom provider, whose educational opportunities are highly valued by the students (47.6\%), is used by teachers to conduct online lectures. Viber has 
become the most common messenger - almost $94 \%$ of respondents indicated that they use it as a tool for distance learning. $12.4 \%$ of respondents reported using Telegram; the least popular was Facebook Messenger (7.1\%). The Google Meet service was also mentioned as the one with great opportunities for remote study, the capabilities of which teachers and students are just beginning to explore. $84.2 \%$ of the surveyed students reported using different combinations of these educational tools for distance learning.

\section{CONCLUSION}

The survey shows that the vast majority of respondents $(86 \%)$ were satisfied with the organization of distance learning at Odessa National Polytechnic University and, in particular, praised the distance work of the teaching staff of the Department of English Philology and Translation Studies (74\% of respondents).

The survey disclosed problems to be solved in order to make distance education effective. The two main drawbacks with the unexpected (hence, mostly unprepared) transition to distance learning are technical difficulties and the underdevelopment of online learning methods and programs.

Elimination of negative factors and shortcomings of distance learning will contribute to:

- providing students with the opportunity to present their knowledge not only in writing but also in verbal form (for example, in webinars);

- solving the problem of user authentication when testing knowledge;

- availability of good technical equipment for using video and audio files;

- development of methods of gradual complication of distance courses with the use of the latest achievements in informational and telecommunication technologies;

- constant feedback between the teacher and the student;

- improvement of students' computer literacy level;

- moral support and material stimulation of remote activity of teachers, etc.

Now that we know strong and weak points of distance teaching and learning, we can take them into account and seek better solutions to improve the quality of education both online and off-line.

\section{REFERENCES}

[1] COVID-19 Education Response, Global Education Coalition, available

at:
https://en.unesco.org/covid19/educationresponse/g lobalcoalition
[2] COVID-19 as a global challenge: towards an inclusive and sustainable future, available at: https://www.thelancet.com/journals/lanplh/article/ PIIS2542-5196(20)30168-6/fulltext/

[3] Remote Learning, available at: https://tophat.com/glossary/r/remote-learning

[4] About Universal Design for Learning, available at: https://www.cast.org/impact/universal-design-forlearning-udl

[5] Oleg Barabash, Andrii Musienko, Spartak Hohoniants, Oleksand Laptiev, Oleg Salash, Yevgen Rudenko and Alla Klochko (2021), "Comprehensive Methods of Evaluation of Efficiency of Distance Learning System Functioning", International Journal of Computer Network and Information Security, vol. 13, no. 1, pp. 16-28. DOI: 10.5815/ijenis.2021.01.02

[6] Google Classroom, available at: https://classroom.google.

[7] Microsoft Teams, available at: https://www.microsoft.com

[8] Zoom, available at: https://zoom.us

[9] MyEnglishLab-Pearson, available at: http://www.myenglishlab.com

[10] Emmanuel G. Dada, Abdulkadir H. Alkali and David O. Oyewola (2019), “An Investigation into the Effectiveness of Asynchronous and Synchronous E-learning Mode on Students' Academic Performance in National Open University (NOUN), Maiduguri Centre", International Journal of Modern Education and Computer Science, vol. 11, no. 5, pp. 54-64. DOI: 10.5815/ijmecs.2019.05.06.

[11] Edmodo, available at: https://new.edmodo.com

[12] Lino, available at: http://en.linoit.com

[13] Wakelet, available at: https://wakelet.com

[14] Nearpod, available at: https://nearpod.com

[15] TED, available at: https://www.ted.com

[16] Abbas Pourhosein Gilakjani, Lai-Mei Leong and Narjes Banou Sabouri (2012), "A Study on the Role of Motivation in Foreign Language Learning and Teaching", IJMECS, vol. 4, no. 7, pp.9-16.

[17] The great distance learning experiment continues: Educators at all levels are grappling with what the changes mean now, and for the future, available at: https://www.apa.org/monitor/2021/01/trendsdistance-learning

[18] Rashid G. Alakbarov (2021), "Challenges of Mobile Devices' Resources and in Communication Channels and their Solutions", International Journal of Computer Network and Information Security, vol. 13, no. 1, pp.39-46. DOI: 10.5815/ijcnis.2021.01.04 